\title{
A Spray Coating and Its Mechanical Properties of Al-Si-Zn Alloy Produced by the Spray Forming Process
}

\author{
Toru Maruyama ${ }^{1}$, Takeshi Kobayashi ${ }^{1}$ and Masatoshi $\mathrm{Kano}^{2, *}$ \\ ${ }^{1}$ Department of Materials Science and Engineering, Faculty of Engineering, Kansai University, Osaka 564-8680, Japan \\ ${ }^{2}$ Department of Materials Science and Engineering, Graduate School of Engineering, Kansai University, Osaka 564-8680, Japan
}

A 55 mass $\%$ Al-1.5 mass $\% \mathrm{Si}-\mathrm{Zn}$ system alloy with good corrosion resistance was sprayed on a plaster substrate. Then, the formation process and some properties of the sprayed coating were investigated. Using the interrupted quenching method, it was found that the sprayed coating structure was not only the layer structure but also a casting structure. Due to large solidification range, the solidification pattern was a mushy type with characteristic of Al-Si-Zn alloys. The maximum temperature and the shrinkage ratio of the sprayed coating decreased as the spray distance increased, due to the decreasing melt particle temperature. Tensile strength and the elongation of the sprayed coating decreased as the spray distance increased, due to an increase in the porosity ratio. In particular, a large amount of oxide was formed in the sprayed coating when air was used as the carrier gas. This oxide formation causes an increase in the shrinkage ratio. [doi:10.2320/matertrans.47.1853]

(Received March 8, 2006; Accepted May 24, 2006; Published July 15, 2006)

Keywords: aluminum-zinc-silicon alloy, flame spraying, formation process, hardness, interrupted quenching, porosity, shrinkage, sprayed coating, sprayed coating property, spray distance, spray forming, tensile strength

\section{Introduction}

The spray forming process leads to production of the sprayed coating with low segregation, fine grains and good mechanical properties. ${ }^{1)}$ The sprayed coating is separated from a substrate. Thus, the view points about adhesion, a cooling rate and a coating thickness are different from the conventional thermal spray process, which is used as a means of surface modification. A metal sprayed coating is deformed by work such as rolling and forging, and sometimes treated as ageing. ${ }^{1,2)}$ However, there are few reports about the net shape process by the spray forming. From the viewpoint of the net shape, it is necessary to avoid coating shrinkage, porosity formation, and coating oxidation.

In this study, for the production of a simple permanent mold, the formation process and coating properties of an Al$\mathrm{Si}-\mathrm{Zn}$ alloy were investigated. $\mathrm{Zn}-\mathrm{Al}$ alloys have been used as a permanent mold for the production of expanded polystyrene. ${ }^{3)}$ However, improvements in strength and corrosion resistance are required. Thus, 55 mass $\%$ Al- 1.5 mass $\% \mathrm{Si}-\mathrm{Zn}$ alloy, named Galvalume, ${ }^{4)}$ was used as the thermal spray powder. The formation process was examined by interrupted quenching. Coating properties such as tensile strength, shrinkage ratio and porosity were investigated.

\section{Experimental Procedures}

\subsection{Spray material and substrate}

Al-Si-Zn alloy powder was used as a thermal spray material. Aluminum and silicon contents were 55 mass $\%$ and 1.5 mass $\%$, respectively. The $\mathrm{Al}-\mathrm{Zn}$ alloy which is called Galuvalume alloy has high corrosion resistance. Silicon was added to the alloy to increase the corrosion resistance and the mechanical properties. The spray powder with a spherical shape was produced by an Ar gas atomization process. The

*Graduate Student, Kansai University. Present address: Aishin Takaoka Co. Ltd., Aichi 473-8501, Japan powder diameter ranged from 20 to $150 \mu \mathrm{m}$, and had a main peak at $75-100 \mu \mathrm{m}$. A plaster substrate for a precision casting was used as the master model. The $10 \mathrm{~mm}$ thick plaster substrate was burned at $523 \mathrm{~K}$ for $10.8 \mathrm{ks} .^{5)}$

\subsection{Method of interrupted quenching and measurement of the sprayed coating properties}

Figure 1 shows a schematic illustration of the apparatus for the interrupted quenching of a sprayed coating. During the thermal spraying, the sprayed coating was dropped into iced water. The interrupted quenching specimen was investigated. A spray material was sprayed on a plaster substrate with a $20 \mathrm{~mm} \times 20 \mathrm{~mm}$ dimension under the condition shown in Table 1. During the thermal spraying process, the fixing pin from the plaster substrate was pulled out, and dropped the substrate into iced water at the preset time. The plaster substrate was slid down into the iced water smoothly. The cross-sectional microstructure of the interrupted quenching specimen was observed. The mean grain size of the primary solidification alpha phase was measured by image analysis equipment. The observation interval was $0.2 \mathrm{~mm}$ from the plaster substrate surface.

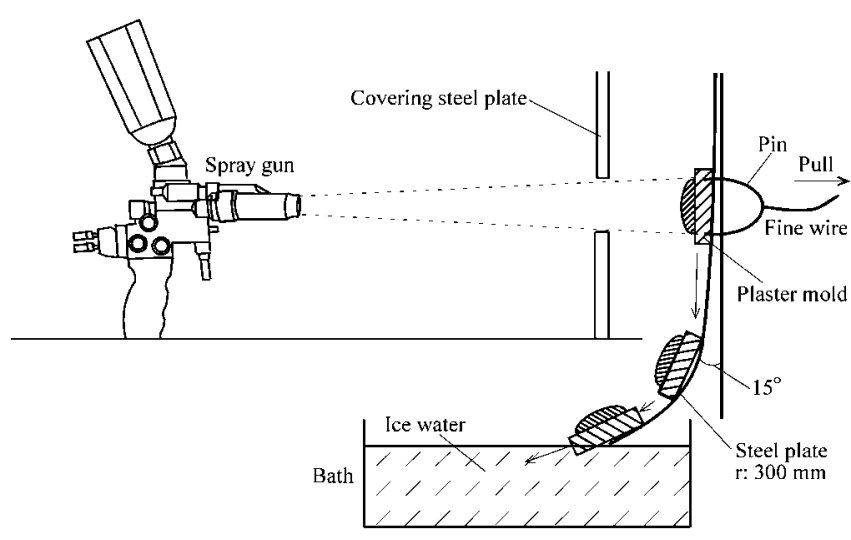

Fig. 1 Schematic illustration of the apparatus for interrupted quenching. 
Table 1 Thermal spraying conditions for observing the interrupted quenching specimen.

\begin{tabular}{|c|c|c|c|c|c|}
\hline \multicolumn{2}{|c|}{$\begin{array}{c}\text { Gas pressure, } \\
P_{C O M} / \mathrm{kPa}\end{array}$} & \multicolumn{2}{|c|}{$\begin{array}{c}\text { Gas flow rate, } \\
F R / \mathrm{m}^{3} \cdot \mathrm{h}^{-1}\end{array}$} & \multirow{2}{*}{$\begin{array}{c}\text { Carrier gas } \\
\text { pressure, } \\
P_{C A R} / \mathrm{kPa}\end{array}$} & \multirow{2}{*}{$\begin{array}{l}\text { Coating } \\
\text { rate, } \\
C R / \mathrm{kg} \cdot \mathrm{h}^{-1}\end{array}$} \\
\hline Acetylene & Oxygen & Acetylene & $\overline{\text { Oxygen }}$ & & \\
\hline 78 & 343 & 1.3 & 1.8 & 21 & 3.6 \\
\hline Exp. No. & \multicolumn{2}{|c|}{$\begin{array}{c}\text { Spray distance, } \\
D_{S T} / \mathrm{mm}\end{array}$} & $\begin{array}{c}\text { Spray time, } \\
t_{s} / \mathrm{s}\end{array}$ & Substrate & Carrier gas \\
\hline 1 & \multirow{2}{*}{\multicolumn{2}{|c|}{$\begin{array}{l}250,300,350 \\
250 \text { (constant) }\end{array}$}} & \multirow{2}{*}{$\begin{array}{c}6 \text { (constant) } \\
3,6,9\end{array}$} & \multirow{2}{*}{ Plaster mold } & Air, $\mathrm{N}_{2}{ }^{*}$ \\
\hline 2 & & & & & Air \\
\hline
\end{tabular}

*Some properties and mechanical properties of the coating were measured.

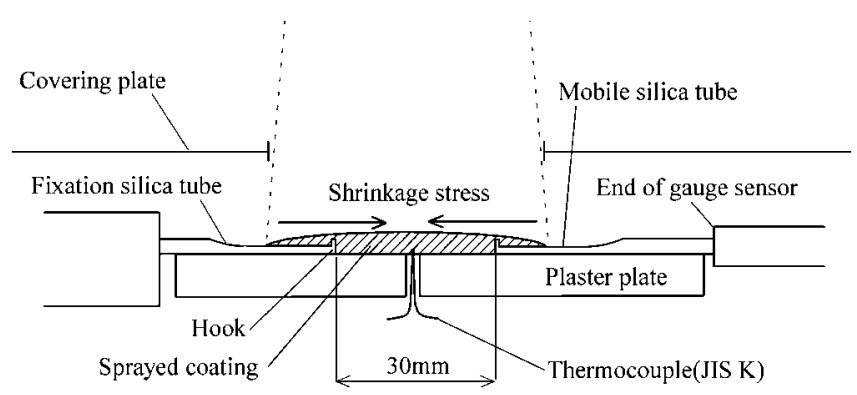

Fig. 2 Schematic illustration of the apparatus for the shrinkage measurement of a sprayed coating.

Table 2 Thermal spraying conditions for the shrinkage measurement of a sprayed coating.

\begin{tabular}{|c|c|c|c|c|c|}
\hline \multicolumn{2}{|c|}{$\begin{array}{c}\text { Gas pressure, } \\
P_{C O M} / \mathrm{kPa}\end{array}$} & \multicolumn{2}{|c|}{$\begin{array}{c}\text { Gas flow rate, } \\
F R / \mathrm{m}^{3} \cdot \mathrm{h}^{-1}\end{array}$} & \multirow{2}{*}{$\begin{array}{c}\text { Carrier gas } \\
\text { pressure, } \\
P_{C A R} / \mathrm{kPa}\end{array}$} & \multirow{2}{*}{$\begin{array}{l}\text { Coating } \\
\text { rate, } \\
C R / \mathrm{kg} \cdot \mathrm{h}^{-1}\end{array}$} \\
\hline Acetylene & Oxygen & Acetylene & Oxygen & & \\
\hline 78 & 343 & 1.3 & 1.8 & 21 & 3.6 \\
\hline Exp. No. & \multicolumn{2}{|c|}{$\begin{array}{c}\text { Spray distance, } \\
D_{S T} / \mathrm{mm}\end{array}$} & $\begin{array}{c}\text { Spray time, } \\
t_{s} / \mathrm{s}\end{array}$ & Substrate & Carrier gas \\
\hline 1 & \multirow{2}{*}{\multicolumn{2}{|c|}{$\begin{array}{l}250,300,350 \\
250 \text { (constant) }\end{array}$}} & \multirow{2}{*}{$\begin{array}{c}10 \text { (constant) } \\
10,15,20\end{array}$} & \multirow{2}{*}{ Plaster mold } & Air, $\mathrm{N}_{2}$ \\
\hline 2 & & & & & Air \\
\hline
\end{tabular}

Spray material: 55.1 mass $\%$ Al-1.5 mass $\% \mathrm{Si}-\mathrm{Zn}$ (bal.) system alloy powder

Figure 2 shows a schematic illustration of the apparatus for measuring shrinkage of the sprayed coating. A boron nitride powder as a parting agent was applied to a plaster substrate with a $100 \mathrm{~mm} \times 110 \mathrm{~mm}$ dimension. Table 2 shows the thermal spraying conditions for the powder flame spraying. Nitrogen gas and argon gas were used as the carrier gases of the spray material. A thermocouple was set on the plaster substrate at the sprayed coating center. The sprayed coating shrinkage on a $30 \mathrm{~mm}$ long line at the sprayed coating center was measured. After measuring the shrinkage, the sprayed coating specimen was removed from the plaster substrate. The cross-section of the removed specimen was observed by an optical microscope. In the microstructure, the porosity looks black, and was evaluated by the measurement of the black area fraction by image analysis. Figure 3 shows an illustration of the tensile test specimen. The specimen was

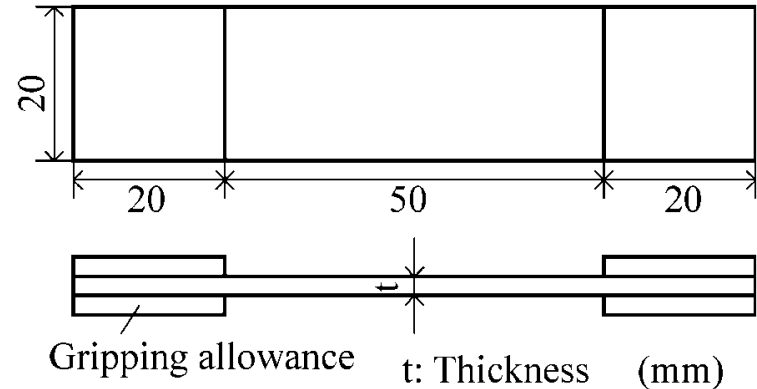

Fig. 3 Shape and size of tensile test specimen.

prepared by cutting it off from the sprayed coating. Tensile strength was measured by a tensile testing machine (Instron type, Shimadzu Autograph DCS-2000). The crosshead speed was fixed to $1.67 \times 10^{-2} \mathrm{~mm} \cdot \mathrm{s}^{-1}$. The hardness of the same specimen was measured by a hardness tester machine.

\section{Results and Discussion}

\subsection{Forming process of the sprayed coating}

Figure 4 shows an example of the microstructure of an interrupted quenching specimen. The grain structure in the region adjoining interface between the plaster substrate and the sprayed coating is an equiaxed structure. The primary solidification phase of the alpha-aluminum exists as equiaxed grains. The silicon phase, which is formed by an eutectic reaction, also exists on the grain boundary. This microstructure represents that a spray particle is rapidly solidified during impact between the spray particle and the plaster substrate. The grain size becomes larger as the distance from the interface to the sprayed coating surface increases. The grain growth seems to be due to heat insulating property of plaster during the solidification of spray particles. On the other hand, fine grains exist in the region close to the sprayed coating surface with a large thickness. It is evident that the fine grains form by rapid solidification during interrupted quenching. In general, a sprayed coating microstructure becomes a layer structure. However, as shown in Fig. 4, the microstructure looks like a casting structure. The formation of a coarse equiaxed structure such as a casting structure is caused by a slow cooling rate due to the plaster substrate.

Figure 5 shows the relationship between the distance from the plaster substrate interface to the sprayed coating surface and the mean grain size of the coating in various interrupted quenching conditions. Mean grain size increases and reaches the peak as the distance from the plaster substrate interface increases. The peak distance corresponds to the position of the boundary between solid and melting states right before interrupted quenching. The melting state might be liquid or slurry because the wide solidification range (about $80 \mathrm{~K}$ ) exists in the 55 mass\%Al-Zn alloy. ${ }^{6}$ ) On the other hand, in the region over the peak distance, the mean grain size decreases as the distance increases. It is evident that grains solidified during interrupted quenching exist in the region over the peak distance. Consequently, the volume fraction of the solidified grains decreases with the peak distance changes toward to the coating surface. This tendency is apparent in the case of the 9 s spraying time shown in Fig. 5(A). As shown in Fig. 5(A), 


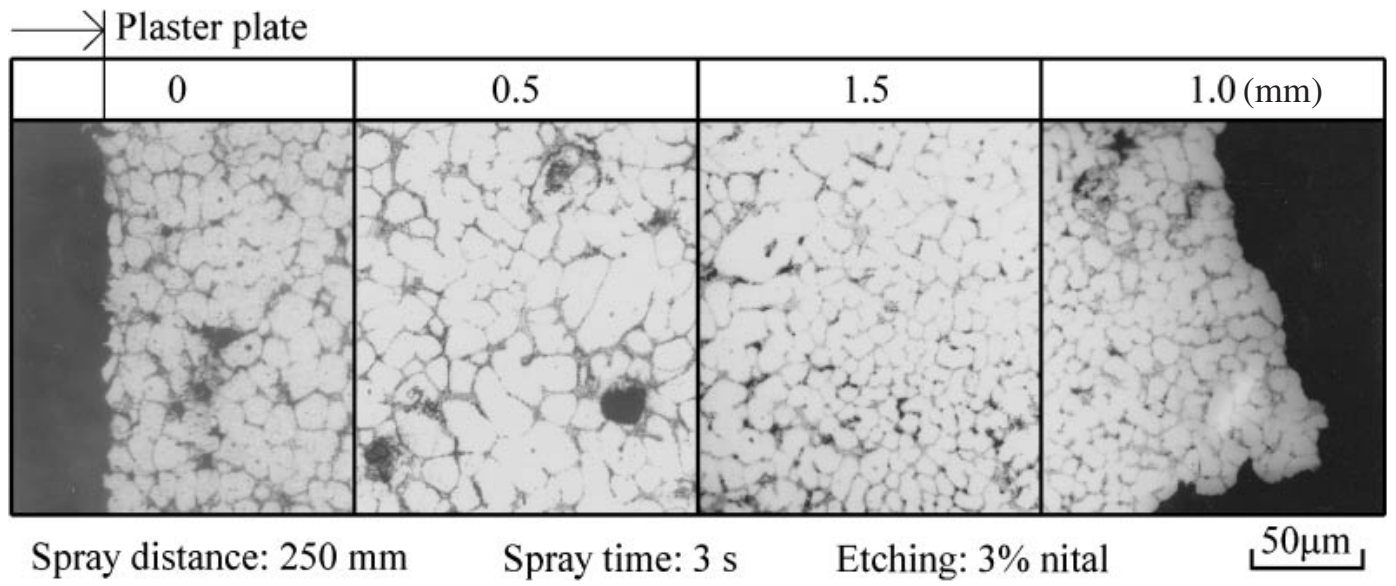

Fig. 4 Microstructure of interrupted quenching specimen.
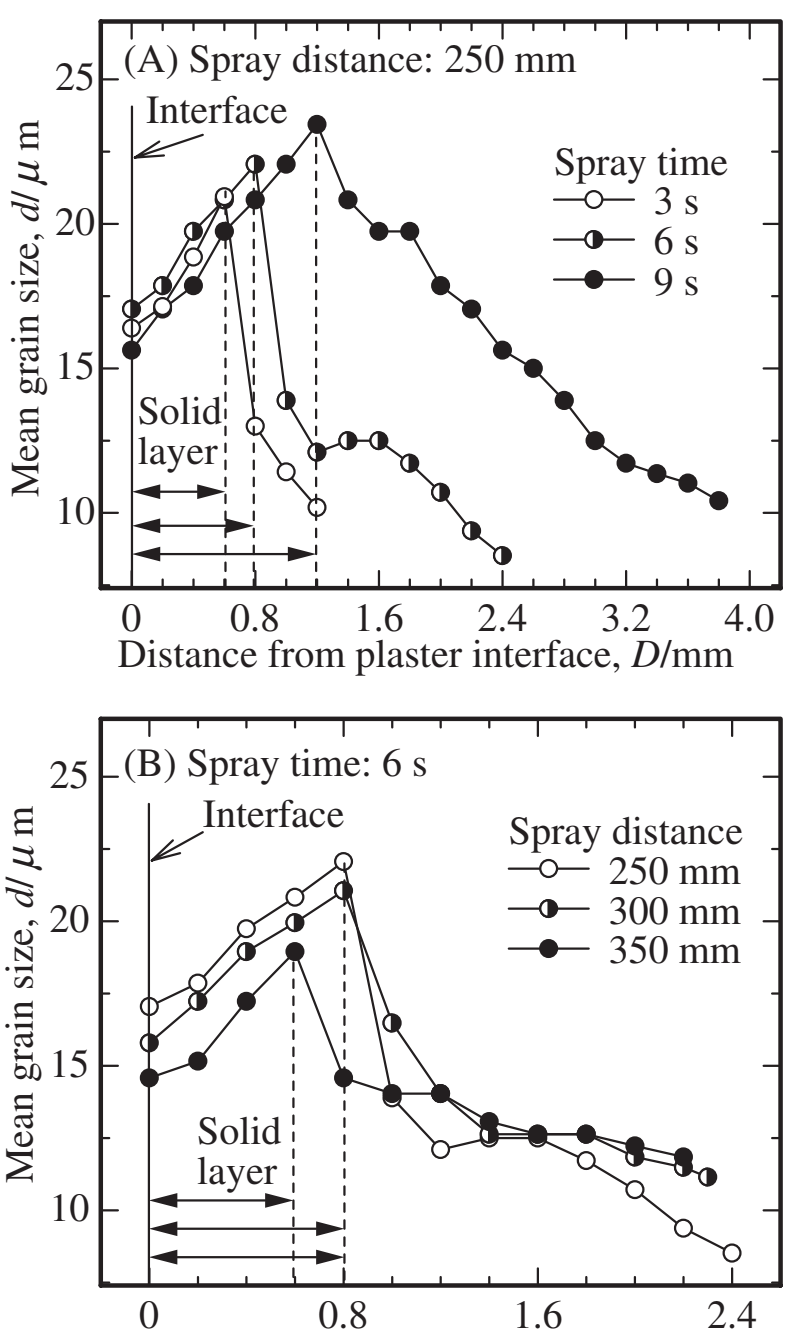

Distance from plaster interface, $D / \mathrm{mm}$

Fig. 5 Relation between distance from plaster substrate interface to the sprayed coating surface and mean grain size of the coating in various interrupted quenching conditions.

the thickness of the sprayed coating increases with the spraying time, because the melt does not flow down the sprayed coating surface. This is attributed to the fact that the melt viscosity is high. There are two reasons for this. First,

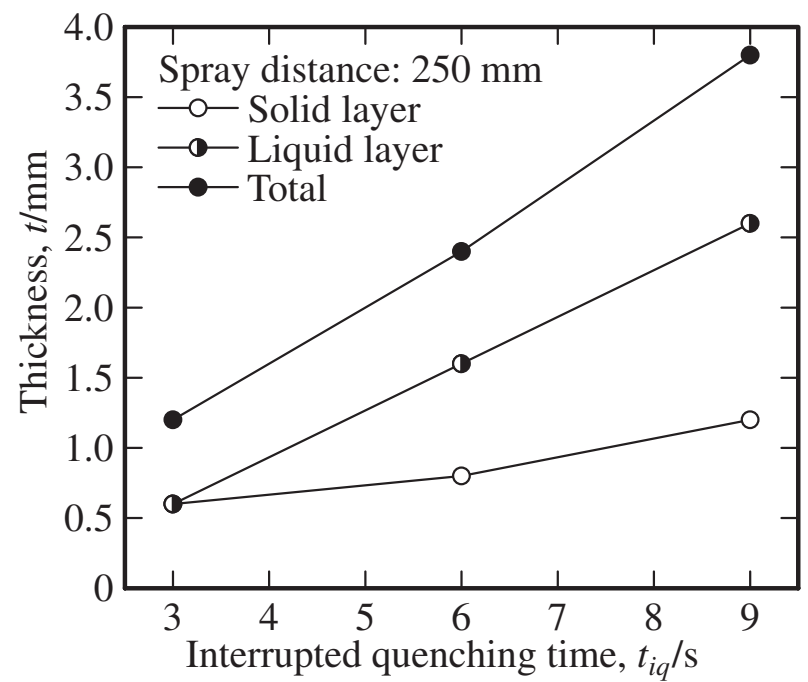

Fig. 6 Relation between interrupted quenching time and thickness of solid and liquid layer in the sprayed coating.

zinc alloying leads to an increase in the viscosity of the aluminum alloy liquid. ${ }^{7)}$ The second is the existence of a semisolid due to the wide solidification range of the Al- $\mathrm{Zn}$ alloy system. If the melt is vigorously stirred, its viscosity decreases as the melt shear rate increases. ${ }^{8)}$ However, the melt shear rate is low due to a low flow rate of the melt. Figure 5(B) shows the effect of the spray distance on the mean grain size. The mean grain size increases with decreasing the spray distance, because the short spray distance causes an increase in the spray particle temperature. Figure 6 shows relationship between the interrupted quenching time and the thickness of the solid and liquid layers in the sprayed coating. The total thickness increases with increasing the interrupted quenching time. However, the increase rate of the solid layer thickness is very small, while the increase rate of the liquid layer thickness is huge. This result means that the increase rate of the melt pool by the melt particle impact is remarkably larger than the solidification rate. An increase in the spray distance leads to a decrease in the thickness of the solid and liquid layers. It is evident that the fly loss of the spray particle increases as the spray distance increases. 


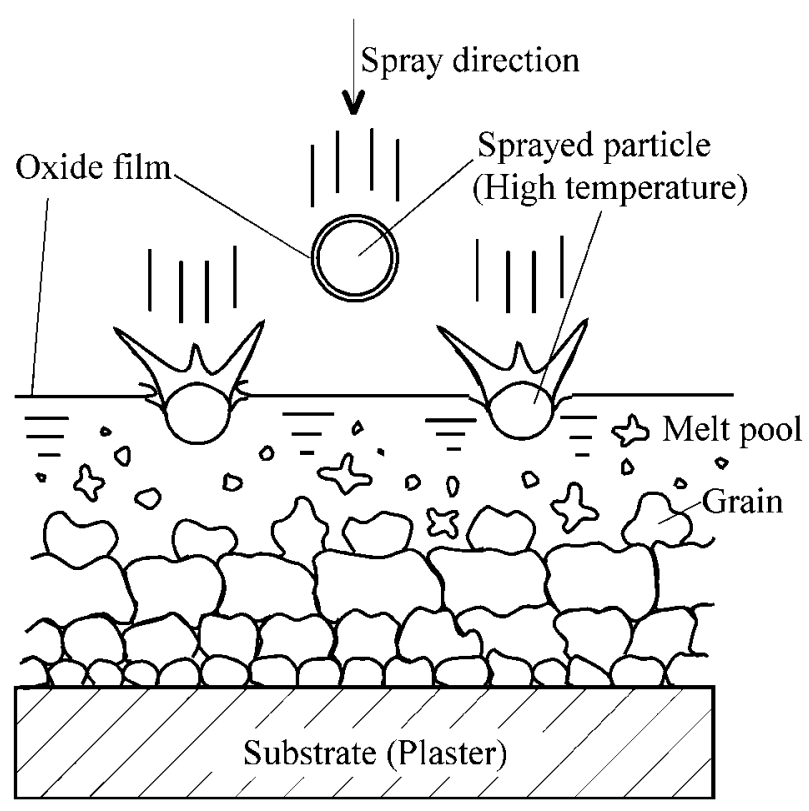

Fig. 7 Schematic diagram of the solidification process of the sprayed coating formed on the plaster substrate.

Figure 7 shows a schematic diagram of the solidification process of the sprayed coating formed on the plaster substrate. The formation process of the 55 mass $\%$ Al- 1.5 mass $\% \mathrm{Si}-\mathrm{Zn}$ alloy sprayed coating is as follows. At first, a sprayed particle is impacted onto the plaster substrate. Fine equiaxed crystals then grow on the plaster substrate. A melt pool is formed because the high temperature sprayed particles accumulate on the equiaxed crystals. The solidification of the sprayed coating is a mushy type due to the wide solidification range. $\left.{ }^{9}\right)$ Therefore, there are large amounts of the solid phase in the melt pool. The surface of the melt pool is covered by the oxide scale. Liquid in the spray particle enters into the melt pool due to the oxide scale failure caused by the impaction between the melt pool and the spray particles. As a result, a high temperature melt exists on the pool surface, and the melt solidifies directionally from the plaster substrate surface to the melt pool surface. It is considered that the sprayed coating structure is formed on the casting structure, as shown in Fig. 4, and that the sprayed coating has low levels of porosity and oxide.

\subsection{Properties of the sprayed coating}

Figure 8 shows effects of time on the temperature and shrinkage of the sprayed coating as a parameter of spray distance. Air was used as a carrier gas. The spray temperature increased as the spraying time increases until the spray finished after $10 \mathrm{~s}$. The temperature reached the maximum at the end of the spraying finish time. After this point, the sprayed coating cooled down slowly. The maximum temperature decreased as the spray distance increased. To understand shrinkage behavior, the thermal properties of the 55.1 mass\% Al-1.5 mass \% Si-Zn alloy were investigated by differential thermal analysis. The alpha Al phase as primary crystal was crystallized at $832 \mathrm{~K}$, and the $\mathrm{Al}-\mathrm{Si}$ eutectic reaction started at $776 \mathrm{~K}$. The $\mathrm{Al}-\mathrm{Zn}$ monotectoid reaction started at $646 \mathrm{~K}$. The maximum temperature in the case of a spray

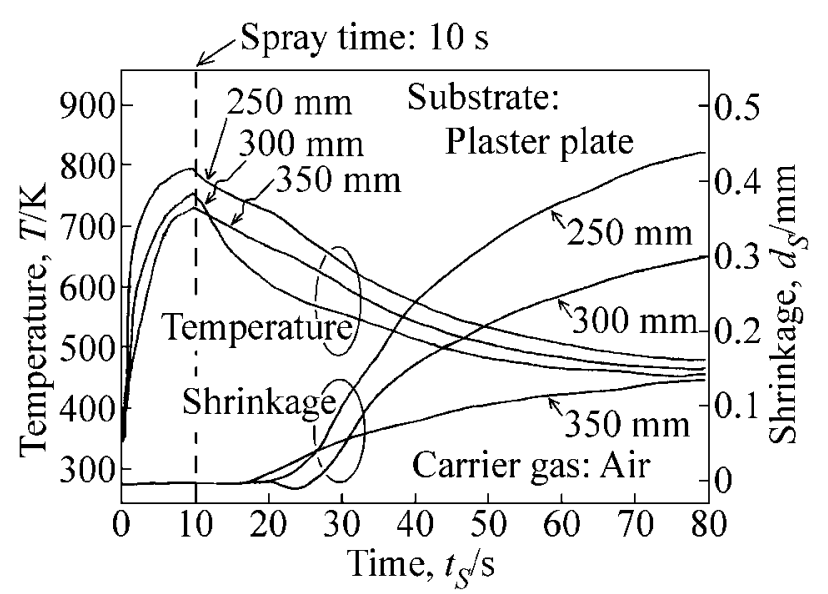

Fig. 8 Effects of time on temperature and shrinkage of sprayed coating as a parameter of spray distance.

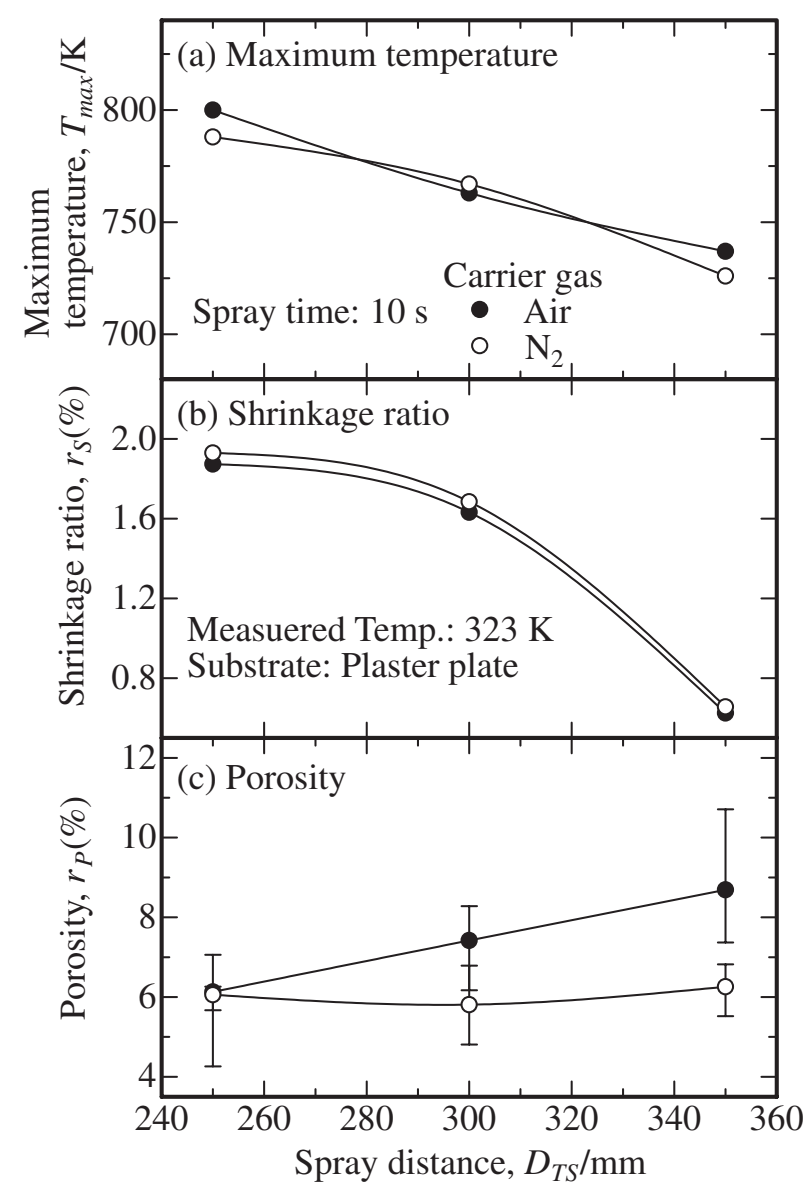

Fig. 9 Effects of spray distance on maximum temperature, shrinkage ratio and porosity of sprayed coating.

distance of $250 \mathrm{~mm}$ was about $800 \mathrm{~K}$, which is lower than the primary crystallization temperature. Shrinkage curves show that the shrinkage started at $650-750 \mathrm{~K}$. The shrinkage increased as the spray distance decreased.

Figure 9 shows the effects of the spray distance on the maximum temperature, the shrinkage ratio and the porosity of the sprayed coating. The maximum temperature decreased as the spray distance increased. The carrier gas had no effect on the maximum temperature. The reason for the maximum 


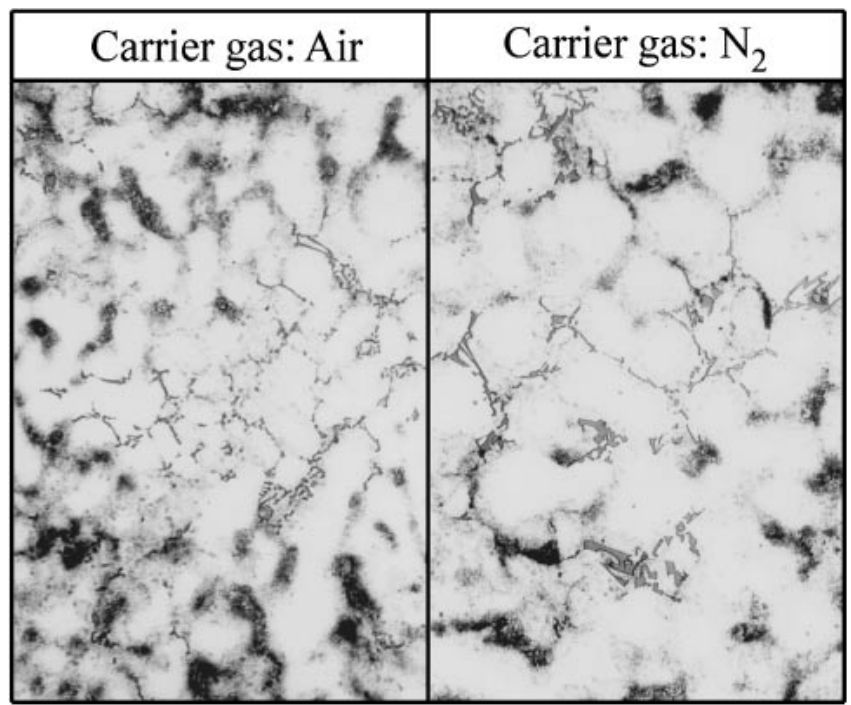

Spray distance: $350 \mathrm{~mm}$

Etching: $1 \% \mathrm{NaOH}$

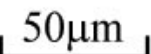

Fig. 10 Microstructure in cross section of sprayed coating.

temperature reduction is that a decrease in the spray distance caused a reduction in the temperature of the sprayed coating. The shrinkage decreased as the spray distance increased. We think that the solid fraction in spray particle increased as the spray distance increased because the temperature of the spray particle decreased as the spray distance increased. Therefore, the solidification shrinkage decreased as the spray distance increased. As shown in Fig. 9(b), the carrier gas had no effect on the shrinkage as with Fig. 9(a). When air was used as carrier gas, the porosity increased as the spray distance increased. The solid fraction also increased as the spray distance increased. It is evident that the increase of the solid fraction caused air intake and the oxidation of the melt spray particle.

Figure 10 shows the microstructure of a cross section of sprayed coating in the case of a spray distance of $350 \mathrm{~mm}$. The equiaxed and white primary crystals solidified, and a needle or plate silicon phase is observed on the grain boundaries. These phases are solidified by an eutectic reaction at the final stage of the solidification process. The microstructures do not change even if air and nitrogen are used as carrier gases. The sprayed coating microstructure seems to be a casting structure, and both porosity and oxide exist on the grain boundaries.

\subsection{Mechanical properties of the sprayed coating}

Figure 11 shows effects of the spray distance on hardness, tensile strength, and the elongation of the sprayed coating. The hardness of the sprayed coating increases as the spray distance increases. The Vickers hardness is almost constant of about a hundred. This is because the increase of the spray distance causes the grain to become fine due to the increase of cooling rate of the sprayed coating, however the increase also causes the increases of porosity and oxide in the sprayed coating. The tensile strength decreases as the spray distance increases, as shown in Fig. 11(b). Using air as the carrier gas

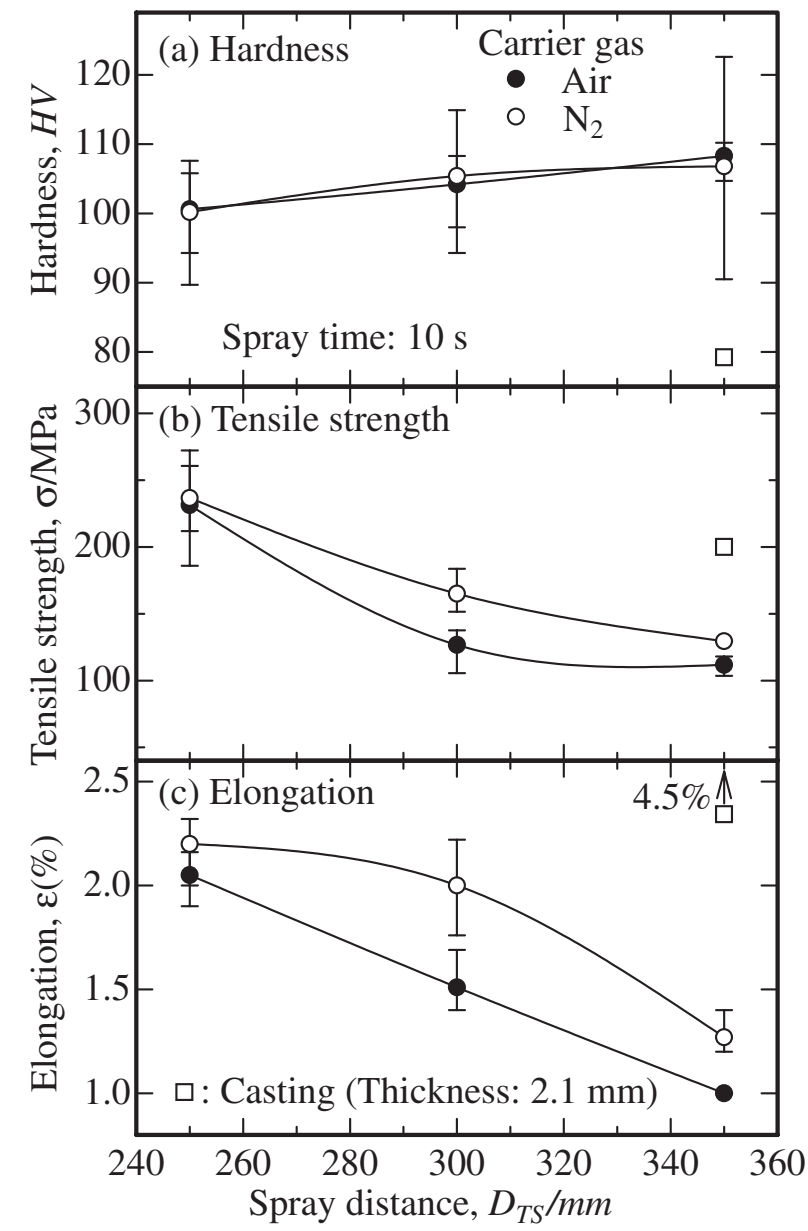

Fig. 11 Effects of spray distance on hardness, tensile strength and elongation of sprayed coating.

leads to low tensile strength. Decreases in tensile strength are caused by air intake, oxidation, and porosity formation. A tensile strength between 110 and $240 \mathrm{MPa}$ is considered to be high enough because the tensile strength of the sprayed coating of a brass and zinc alloy including $\mathrm{Cu}$ and $\mathrm{Ti}$ is about $10 \mathrm{MPa} .{ }^{10,11)}$ In our previous study, ${ }^{12)}$ the tensile strength of the 55.1 mass \%Al-1.50 mass\%Si-Zn alloy sprayed coating showed that it was five times stronger than a pure metal sprayed coating of zinc and aluminum. In general, the tensile strength of the $\mathrm{Zn}-\mathrm{Al}$ alloy casting is high. In particular, the tensile strength of the $\mathrm{Zn}-27$ mass\%Al alloy is more than $400 \mathrm{MPa} .{ }^{13,14)}$ The tensile strength of the sprayed coating is comparable with that of the casting. The tensile strengths of the sprayed coatings sprayed onto a plaster substrate are large due to the low porosity ratio; this is because the cooling rate is small. As shown in Fig. 11(c), the elongation of the sprayed coatings decreases as the spray distance increases, since the porosity ratio increases with increasing spray distance as shown in Fig. 9. The elongation of the casting is about two times larger than the value of the sprayed coatings. This result means the effect of the porosity ratio is significant.

Figure 12 shows the microstructure of a longitudinal section of a rupture specimen. The Al-Si eutectic structure, and porosity lead to the propagation path and the initiation sited of cracks. 


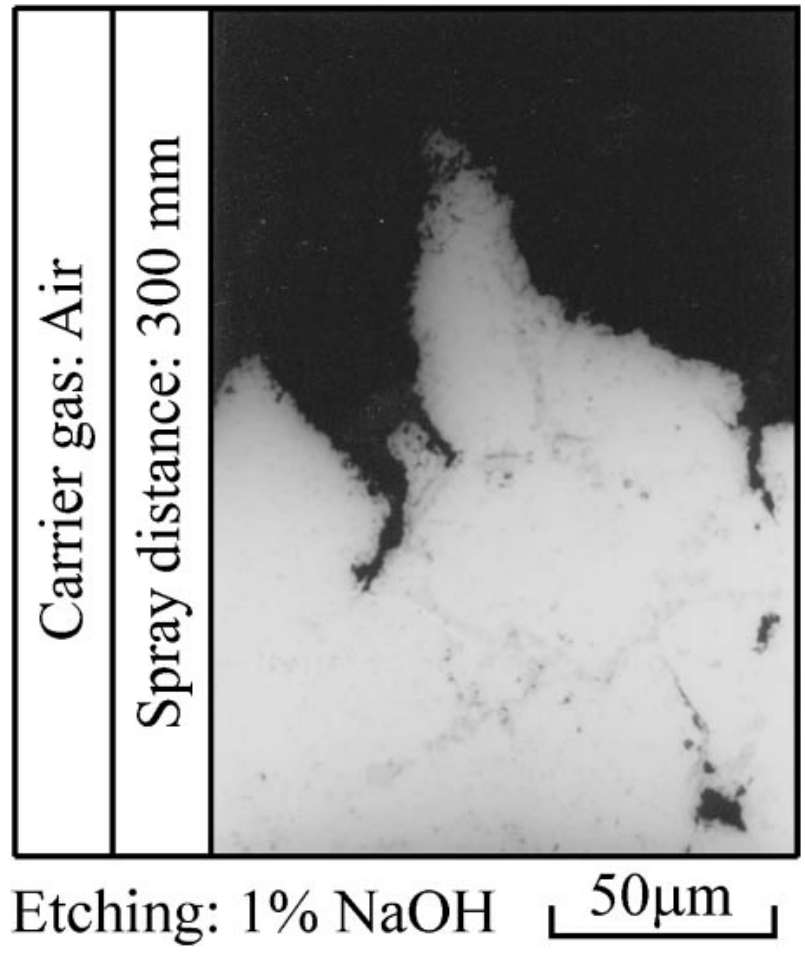

Fig. 12 Microstructure of a longitudinal section on rupture specimen.

\section{Conclusions}

On the Al-Si-Zn system alloy sprayed coating, we investigated the formation process and mechanical properties, and obtained the following results:

(1) The solidification type of the semisolid of an Al-Si-Zn system alloy sprayed to a plaster substrate is mushy type. The grain structure of the sprayed coating is a coarse eqiaxed structure due to a slow cooling rate of the sprayed coating on the plaster substrate. Microstructure observation using the interrupted quenching specimen showed that the sprayed coating structure is not only the layer structure which is commonly observed in general sprayed coating but also a casting structure.

(2) The grain size in the sprayed coating increases as the semisolid layer thickness increases, due to large spraying time.
(3) The maximum temperature of an Al-Si-Zn system alloy sprayed coating increases as the spray distance increases. The increase of the spray distance leads to the decrease of temperature of spray particle flying, and the shrinkage ratio decreases.

(4) The porosity ratio increases as the spray distance increases, especially, using an air gas as a carrier gas. This result is due to an oxidation of the melt particle surface in air.

(5) The tensile strength and the elongation of the sprayed coating decrease as the spray distance increases, again due to an oxidation of the melt particle surface in air. The tensile strength is at the same level as that of an ascast material.

This is a product of research which was financially supported in part by the Kansai University Research Grants: Grant-in-Aid for Encouragement of Scientists, 2003.

\section{REFERENCES}

1) A. R. E. Singer: Rev. Metall. 85 (1988) 681-686.

2) V. C. Srivastava, A. Schneider, V. Uhlenwinkel, S. N. Ojha and K. Bauckhage: J. Mater. Proc. Technol. 147 (2004) 174-180.

3) Japan Lead and Zinc Development Association: Zinc handbook, (The Nikkan Kogyo Shinbun, Tokyo, 1977) pp. 343-346.

4) Japan Lead and Zinc Development Association: Lead and Zinc 16 (1979) 15-22.

5) A. J. Clegg: Precision Casting Process, (Pergamon Press, UK, 1991) pp. 110-122.

6) T. B. Massalski: Binary Alloy Phase Diagrams/2nd ed. Vol. 1, (ASM International, Materials Park, 1990) pp. 239-241.

7) Y. Kawai and Y. Shiraishi: Handbook of Physico-Chemical Properties at High Temperatures, (The Iron and Steel Institute of Japan, Tokyo, 1998) pp. 101.

8) The Society of Rheology: Koza.Rheology, (Kobunshi Kankokai, Kyoto, 1992) pp. 13-20.

9) ASM International Handbook Committee: Metals Handbook/9th ed. Vol. 15 Casting, (ASM International, Materials Park, 1988) pp. 579580 .

10) N. Hara, H. Noji, N. Kariyama, N. Hata, M. Murata, Y. Fujimoto, A. Aramoto, N. Dehari, I. Higashiyama, H. Kawano, H. Kiyama and K. Sasaki: Bulletin of The Western Hiroshima Prefecture Industrial Research Institute 33 (1990) 55-58.

11) N. Hara and H. Noji: Thermal Spraying Technique 15/3 (1995) 46-51.

12) T. Kobayashi, T. Maruyama and M. Kano: Mater. Trans. 44 (2003) 2711-2717.

13) K. H. Matucha: Mater. Sci. Technol. 8 (1995) 102-103.

14) S. W. K. Morgan: Zinc and Its Alloys and Compounds, (Ellis Horwood Limited, Chichester, 1985) pp. 186-189. 